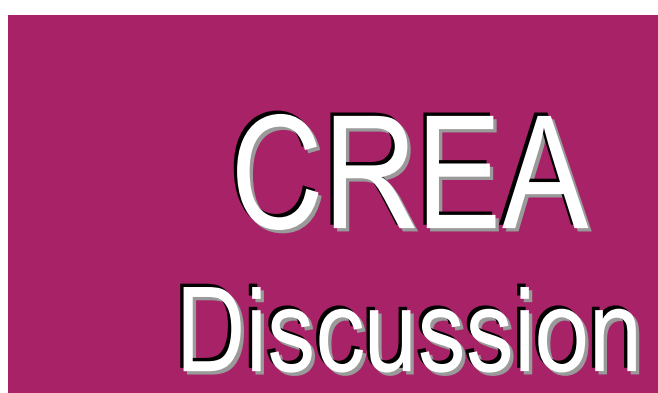
Paper 2019-09 Economics

\title{
Is a dynamic approach of tax games relevant?
}

available online : http://wwwfr.uni.lu/recherche/fdef/crea/publications/discussion_papers

Nora Paulus, CREA, University of Luxembourg Patrice Pierreti, CREA, University of Luxembourg

Benteng Zou, CREA, University of Luxembourg

Juin, 2019

For editorial correspondence, please contact: crea@uni.lu University of Luxembourg Faculty of Law, Economics and Finance

162A, avenue de la Faïencerie L-1511 Luxembourg 


\title{
Is a dynamic approach of tax games relevant? *
}

\author{
Nora Paulus ${ }^{\dagger}$ Patrice Pieretti $\ddagger^{\ddagger}$ Benteng Zou ${ }^{\S}$
}

\begin{abstract}
In this paper we argue that static models provide an incomplete analysis of interjurisdictional tax competition.

According to Wilson (1987) a static tax competition model might predict the long-run outcomes of government decision making in a dynamic setting. We show that this conjecture is only true when policymakers commit to a tax path at the start of the game without future updates (open-loop behavior), with the proviso that they are time-indifferent and/or capital is perfectly mobile. Static models however never predict future outcomes when policymarkers continuously update their tax rates (Markovian behavior). In particular, we address the following aspects. How do long-run outcomes in a dynamic setting change relative to static games? How does social welfare change accordingly? If policymakers have the choice, which strategical behavior (Markovian or open-loop) should they adopt? In light of this, which one confers the highest social advantage?
\end{abstract}

Keywords: Dynamic Tax Competition, Differential Games, Markovian Nash Equilibrium, Open-loop Strategy

JEL classification: $\mathrm{C} 73, \mathrm{~F} 21, \mathrm{H} 21, \mathrm{H} 87$

${ }^{*}$ We are in debt to David Wildasin for inspirational comments. We thank Raouf Boucekkine, Herbert Dawid, Wolfgang Eggert and Pierre Picard for helpful suggestions. We appreciate the comments from the 14th Viennese Conference on Optimal Control and Dynamic Games and the 10th Lisbon Meetings in Game Theory and Applications. All remaining errors are ours.

${ }^{\dagger}$ CREA, University of Luxembourg, 162a, avenue de la Faencerie, L-1511, Luxembourg. E-mail: nora.paulus@uni.lu.

${ }^{\ddagger}$ CREA, University of Luxembourg, 162a, avenue de la Faencerie, L-1511, Luxembourg. E-mail: patrice.pieretti@uni.lu.

${ }^{\S}$ Corresponding author. CREA, University of Luxembourg, 162a, avenue de la Faencerie, L-1511, Luxembourg. E-mail: benteng.zou@uni.lu. This author acknowledges the financial support from the NSFC project 71573230. 


\section{Introduction}

Interjurisdictional tax competition for internationally mobile production factors by means of an attractive tax system is a commonly observed and pervasive phenomenon. Indeed, national tax policies can be seen as one of the key factors that determine investors' and firms' decisions of where to invest capital. Empirical research dealing with the effects of international taxation on foreign direct investment has shown that a reduction in a country's tax rate raises foreign direct investment1. In other words, investors and firms react to changes in jurisdictions' tax rates and reallocate their capital stock accordingly. Wildasin $(2003,2011)$ characterizes this movement of capital as a process that takes time and doesn't occur instantaneously. In fact, investment allocations need time to adjust $2^{2}$ and capital flows between jurisdictions take more or less time according to the speed of capital adjustments.

However, the existing literature on tax competition is mainly based on static models, in which capital stocks adjust instantaneously to policy changes and tax rates don't evolve over time (see for example Kanbur and Keen, 1993; Wilson, 1999; Wilson and Wildasin, 2004). According to Wilson (1987) a static tax competition model might predict the long-run outcomes of government decision making in a dynamic setting. In the present paper we show that this conjecture is only true when jurisdictions commit to a tax path at the start of the game without future updates (open-loop behavior) with the proviso that they are perfectly "time-indifferent" and/or capital is perfectly mobile. However, static models never predict future outcomes when the competing governments continuously update their tax rates according to the country's capital stock (Markovian behavior). In other words, the steady state equilibrium in the Markovian case does not coincide with the equilibrium of a static model game. This is consistent with Wilson's (1987) statement that "there still remains a need for an explicit treatment of the dynamic issues".

Among the few papers covering dynamic issues related to interjurisdictional competition are the seminal contributions of Wildasin $(2003,2011)$. Fundamentally, Wildasin $(2003,2011)$ analyzes the dynamic process of competition for capital in a time-invariant tax rate framework and highlights the fact that capital stocks need time to adjust to policy changes. In fact, the dynamics in Wildasin's models result from the introduction of adjustment costs which preclude the instan-

\footnotetext{
${ }^{1}$ See for example Hartmann (1984, 1985); Slemrod (1990 a and b); Devereux and Freeman (1995) and more recently, Altshuler and Grubert, (2006) who use American data of multinational companies; Becker and Riedel (2012) and Becker, Fuest and Riedel (2012) who use data on European foreign direct investments .

${ }^{2}$ According to Wildasin $(2003,2011)$, the speed of capital-stock adjustments depends on various factors (e.g. the distance between the competing jurisdictions, the speed with which production facilities can be relocated, etc.).
} 
taneous adjustment of capital to changes in the tax policies. According to Becker (2005), the adjustment speed in Wildasin (2003) can be interpreted as a measure of capital mobility, allowing to focus on the more realistic cases, which are in between the two extremes, namely autarky and perfect integration. Nonetheless, in the models of Wildasin $(2003,2011)$ tax rates are exogenously given and don't evolve over time.

The dynamics developed in this paper are determined by both, changing tax rates and sluggish capital adjustment. More precisely, we model the interplay between tax rates and capital stocks by the fact that changes in tax rates induce firms to reallocate capital between competing jurisdictions. Capital flowing in and out of a given country in turn, affects the tax rates set by the policymakers.

The closest settings to ours are the contributions of Han et al. (2014) and Kato (2015) who analyze dynamic tax competition in differential-game settings with tax rates that change over time. In Han et al. (2014) two unequally sized countries compete for mobile capital with two instruments (namely taxes and infrastructure) ${ }^{3}$. Kato (2015) investigates the effect of agglomeration forces on the nature of tax competition and international trade. However, the purpose of these contributions differs from ours. Our paper, contrary to the previous authors, focuses on how different ways to model dynamic tax competition (open-loop and Markovian games) differ from one another and from a static view regarding the equilibrium tax (subsidy) rates and their welfare implications.

The choice between an open-loop and a closed-loop (Markovian) behavior by the competing jurisdictions can be explained for various reasons. Governments may opt for an open-loop behavior to provide a stable environment to foreign firms by guaranteeing a predetermined tax rate for a given period. For example, between 1998 and 2003 the Irish government lowered its corporate tax rate from $45 \%$ to $12,5 \%$ and remained committed to this rate ever since. Moreover, commitment to a path of future tax rates could be imposed by international agreements in order to mitigate tax competition. Finally, governments may be constrained to adopt an open-loop strategy because of the existence of update costs. Indeed, after having decided on a given tax rate, changing rates notably requires a minimal political consensus, which may be more or less time-consuming. Commitment to an initial policy path could thus save costs. However, commitment strategies also have negative aspects. According to Kato (2015) "credible policies imply that governments promise to keep their original policies even if they are aware that the policies are no longer optimal". Indeed, open-loop strategies preclude reactions to rivals' tax changes. By contrast, Markovian feed-back

\footnotetext{
${ }^{3}$ The dynamic setting used by the authors can only be applied to analyze competition between asymmetric countries.
} 
strategies are less vulnerable to their rivals' policy changes.

In this paper we mainly focus on steady states resulting from open-loop and Markovian games. In this context, the following aspects are mainly analyzed. How do long run outcomes change relative to static games? How does social welfare change accordingly? If jurisdictions have the choice, which strategical behavior (Markovian or open-loop) should they adopt ? In light of this, which one confers the highest social advantage?

To answer these questions, we develop a dynamic game with the following features. Two competing jurisdictions are considered. A multinational company (MNC) uses capital and labor to produce a final good sold on a competitive market and the profits are taxed proportionally. Moreover, the MNC contemplates investing capital in two different jurisdictions, which do not compete in taxes at an initial date. Then, countries start competing in taxes to attract mobile capital. The tax rates are set to maximize countries' social welfare reflecting private and public expenditures. This induces the MNC to reallocate capital between the two jurisdictions. As mentioned above, the allocation of capital adjusts progressively, depending on the speed with which capital flows from one jurisdiction to another.

The main results of the paper can be summarized as follows. We demonstrate that the intensity of tax competition, measured by the level of equilibrium tax (subsidy) rates, is impacted by the temporal nature of the game. In particular, tax competition is fiercer in a dynamic setting relative to a static one if governments adopt a Markovian-feedback behavior assuming that capital can be relocated easily and the policymakers put a relatively low weight on public consumption. As a result, social welfare is relatively lower in a dynamic setting. However, if the competing governments adopt an open-loop behavior, tax competition is less fierce relative to a static game. This follows from the fact that governments commit to a predetermined path of tax rates without future adjustments. Given that this softens competition, social welfare will be higher in an openloop framework relative to a static world. Moreover, tax competition is fiercer in a Markovian game relative to an open-loop setting. Consequently, social welfare is relatively lower in the first case. Finally, the model shows that the governments can either compete in taxes or provide subsidies to attract foreign capital. The governments' decision to tax profits or to grant subsidies depends on how much they weigh up private against public consumption.

Our paper is organized as follows. The next section presents the general setting of the model. In Section 3, the profit functions of the firms are specified. In Section 4, a static tax game is developed as a benchmark. In Section 5 and 6, stationary open-loop and Markovian Nash equilibria are 
derived. Section 7 compares the equilibria of the dynamic game with the benchmark case. The last section concludes and discusses possible extensions.

\section{The model setting}

In this section, we develop a model of tax game and dynamic capital allocation. In addition to that open-loop and Markovian Nash equilibria are defined.

\subsection{Dynamic capital allocation}

Consider that a multinational company (MNC) decides to invest in two locations, namely countries 1 and 2. To this end, it sets up a subsidiary company that hires capital and workers to produce one homogeneous good that is sold in a competitive market at a given price $p$ normalized to 1 . Capital is mobile across the countries, while labor is not. As in Bucovetsky and Smart (2006) and Eggert and Itaya (2014), we assume that labor inputs are fixed for each company and we normalize the given wage rate $w$ to zero. The rate of return on invested capital equals the world interest rate $r$ that is exogenously given. Each subsidiary employs a given amount of per capita capital $\bar{k}$ (normalized to 1 ) that is invested in the locations 1 and/or 2. More precisely, the MNC invests $k_{1} \in[0,1]$ and $k_{2}=\bar{k}-k_{1} \in[0,1]$ in countries 1 and 2 , respectively.

Moreover, we consider that the profit of a subsidiary (before tax) profit in country $j(=1,2)$ is a function of capital per capita:

$$
\pi_{j}=f\left(k_{j}\right)
$$

We assume that the economy at time $t=t_{0}$ is in a steady-state where countries 1 and 2 do not compete in taxes. Both countries set non-strategic tax rates ${ }^{4} \tau_{1}^{0}$ and $\tau_{2}^{0}$ that have been determined by pure domestic considerations. In the following, we assume that the MNC decides to invest in country $j(=1,2)$ subject to the participation constraint $\left(1-\tau_{1}^{0}\right) \pi_{j} \geq 0$.

The multinational chooses its investment levels in countries 1 and/or 2 to maximize total profit net of taxes given by $\Omega^{0}=\left(1-\tau_{1}^{0}\right) \pi_{1}^{0}+\left(1-\tau_{2}^{0}\right) \pi_{2}^{0}$. We assume that the initial tax rates are

\footnotetext{
${ }^{4}$ Notice that the tax rates $\tau_{j}$ with $j \in\{1,2\}$ are choice variables. This means that we cannot impose initial conditions on them. Nevertheless, we can take them as given before the game starts.
} 
different across the countries. It follows that the the initial capital shares $k_{1}^{0}$ and $k_{2}^{0}$ resulting from profit maximization will be different.

Now consider that at $t>t_{0}$ policymakers of countries 1 and 2 start competing in taxes. This induces the MNC to reallocate its capital between the two jurisdictions according to the net marginal profit of their investments. The reallocation of capital doesn't occur instantaneously. According to Wildasin (2003, 2011), the speed of adjustment of physical capital depends on various factors (e.g. the moving costs between the competing jurisdictions, the speed with which new investments can be implemented). The variation of capital invested in country $15^{5}$ is given by the following motion equation

$$
\dot{k}_{1}(t)=\gamma\left[\left(1-\tau_{1}\right) \frac{\partial \pi_{1}}{\partial k_{1}}-\left(1-\tau_{2}\right) \frac{\partial \pi_{2}}{\partial k_{2}}\right]
$$

where the parameter $\gamma$ denotes the speed of capital reallocation. In our model, the capital stock allocated at each date between the competing jurisdictions is the relevant state variable. If $\dot{k}_{1}(t)>$ 0, capital moves from country 2 to country 1 , and from country 1 to country 2 if $\dot{k}_{1}(t)<0$.

When $\gamma=0$, the MNC does not reallocate any capital between the jurisdictions. If we divide equation (1) by $\gamma$, with $\gamma \rightarrow+\infty$, we obtain

$$
\lim _{\gamma \rightarrow+\infty} \frac{\dot{k}_{1}(t)}{\gamma}=0=\left(1-\tau_{1}\right) \frac{\partial \pi_{1}}{\partial k_{1}}-\left(1-\tau_{2}\right) \frac{\partial \pi_{2}}{\partial k_{2}} .
$$

In other words, when the parameter $\gamma$ tends to infinity, the adjustment takes place instantaneously and the system jumps to its steady state.

\subsection{Dynamic tax game: open-loop and Markovian decision rules}

The competing jurisdictions choose their tax path $\left[\tau_{j}(t)\right]_{t \in(0, \infty)}$ that maximizes their social welfare $\Omega_{j}(t)$ over an infinite time horizon subject to the above motion equation assuming that the rival's

\footnotetext{
${ }^{5}$ The motion equation of capital invested in country 2 can be written symmetrically by considering that$$
\dot{k}_{2}(t)=-\dot{k}_{1}(t)
$$ 
tax path is given. The social welfare function $\Omega_{j}(t)$ at time $t$ is defined as follows:

$$
\Omega_{j}(t)=\left(q_{j}-\tau_{j} \pi_{j}\right)+\theta \tau_{j} \pi_{j}
$$

This function combines both private and public consumption. The first term in (2) is the output $\left(q_{j}\right)$ minus the tax income on profit $\left(\tau_{j} \pi_{j}\right)$ generated in country $j(=1,2)$ that equals private consumption expenditures. The second term in (2) represents the total tax revenue collected in country $j(=1,2)$ used for financing public consumption. The parameter $\theta>1$ measures the social preference for public expenditures relative to private consumption. ${ }^{6}$ Thus, the decision maker of country $j(=1,2)$ faces the following optimization problem:

$$
\begin{gathered}
\max _{\tau_{j}} J_{j}=\int_{0}^{\infty} e^{-\rho t} \Omega_{j}(t) d t=\int_{0}^{\infty} e^{-\rho t}\left[\left(q_{j}-\tau_{j} \pi_{j}\right)+\theta \tau_{j} \pi_{j}\right] d t \\
\text { s.t. } \dot{k}_{1}(t)=\gamma\left[\left(1-\tau_{1}\right) \frac{\partial \pi_{1}}{\partial k_{1}}-\left(1-\tau_{2}\right) \frac{\partial \pi_{2}}{\partial k_{2}}\right] .
\end{gathered}
$$

The parameter $\rho$ is a discount rate reflecting the degree of impatience of the home population. The discount factor $\rho$ is supposed to be the same for both countries. In this paper we model a dynamic tax game in two alternative ways. The jurisdictions adopt either an open-loop or a Markovian decision rule. Accordingly, we define the following equilibria.

Definition 1 A 2-tuple $\left(\tau_{1}, \tau_{2}\right)$ of functions $\tau_{j}(t):[0,+\infty) \rightarrow R, j(=1,2)$, is called an open-loop Nash equilibrium if, for each $j(=1,2)$, an optimal path $\tau_{j}(\cdot)$ of the problem (3) exists and is given by the open-loop strategy $\tau_{j}=\tau_{j}(t)$.

The Hamiltonian function of country $j(=1,2)$ is defined as follows

$$
\mathcal{H}_{j}\left(\tau_{j}, k_{j}, \lambda_{j}\right)=\left[\left(q_{j}-\tau_{j} \pi_{j}\right)+\theta \tau_{j} \pi_{j}\right]+\gamma \lambda_{j}\left[\left(1-\tau_{1}\right) \frac{\partial \pi_{1}}{\partial k_{1}}-\left(1-\tau_{2}\right) \frac{\partial \pi_{2}}{\partial k_{2}}\right] .
$$

We refer ${ }^{7}$ to Dockner at al. (2000) to establish the existence of an open-loop equilibrium. In the following sections, we provide the explicit Nash equilibria using a specific production function.

Definition 2 A 2-tuple $\left(\tau_{1}, \tau_{2}\right)$ of functions $\tau_{j}:[0,1] \times[0,+\infty) \rightarrow R, j(=1,2)$ is called a

\footnotetext{
${ }^{6}$ Note that $\Omega_{j} \rightarrow \tau_{j} \pi_{j}$ when $\theta \rightarrow+\infty$. In this case, decision makers maximize public consumption only.

${ }^{7}$ See Theorem 4.2. In Dockner et al. (2000)
} 
Markovian Nash equilibrium if, for each $j(=1,2)$, an optimal path $\tau_{j}(\cdot)$ of the problem (3) exists and is given by the Markovian strategy $\tau_{j}=\tau_{j}\left(k_{j}(t), t\right)$.

We denote the stationary ${ }^{8}$ Bellman value function of policymaker $j$ by $V_{j}$. The Hamilton-JacobiBellman is defined as follows:

$$
\left.\rho V_{j}=\max _{\tau_{j}}\left[\left(\left(q_{j}-\tau_{j} \pi_{j}\right)+\theta \tau_{j} \pi_{j}\right)+\frac{\partial V_{j}}{\partial k_{j}} \gamma\left[\left(1-\tau_{1}\right) \frac{\partial \pi_{1}}{\partial k_{1}}-\left(1-\tau_{2}\right) \frac{\partial \pi_{2}}{\partial k_{2}}\right)\right]\right] .
$$

We again refer $9^{9}$ to Dockner et al. (2000) to show that under the current setting the solution of the Hamilton-Jacobi-Bellman equation provides a sub-game perfect Markovian Nash equilibrium.

\section{Special case: Linear-quadratic profit function}

In order to determine the optimal tax strategies of each government, we need to specify the firms' production function.

Assume that the MNC produces $q_{j}$ units in country $j(=1,2)$ according to the following linearquadratic production function

$$
q_{j}=\alpha k_{j}-\frac{k_{j}^{2}}{2},
$$

where $\alpha \geq 1+r$ is a technological coefficient. The production function verifies the standard properties $f^{\prime}\left(k_{j}\right)>0$ and $f^{\prime \prime}\left(k_{j}\right)<0$. The concavity results from the fact that capital is the only variable input. Accordingly, the MNC's pre-tax profit function in country $j(=1,2)$ becomes $\pi_{j}=(\alpha-r) k_{j}-\frac{k_{j}^{2}}{2}$, given that the market price of the final good is normalized to 1 . In the following, we set $a=\alpha-r$ and assume that the MNC allocates its capital in country $j(=1,2)$ by maximizing its after tax profit $\left(1-\tau_{j}\right) \pi_{j}$ subject to the participation constraint $\left(1-\tau_{j}\right) \pi_{j} \geq 0$. It follows that

$$
\pi_{j}=a k_{j}-\frac{k_{j}^{2}}{2}
$$

\footnotetext{
${ }^{8}$ Generally, the value function $V_{j}$ is not just a function of the state variable $k_{j}$ but also a function of time $t$. Kamien and Schwartz (1981, p. 238) have already shown that if time enters the objective function only through the discount term then the value functions do not depend on time $t$ explicitly.

${ }^{9}$ See Theorem 4.1 in Dockner et al. (2000)
} 
For the sake of simplicity we normalize $\alpha$ to 1and $r=0$. It follows that $q_{j}=\pi_{j}$ and the welfare function at time $t$ in country $j(=1,2)$ becomes $\Omega_{j}(t)=\left(1-\tau_{j}\right) \pi_{j}+\theta \tau_{j} \pi_{j}$.

Moreover, the motion equation can be written

$$
\begin{aligned}
\dot{k}_{1}(t) & =\gamma\left[\left(1-\tau_{1}\right) \frac{\partial \pi_{1}}{\partial k_{1}}-\left(1-\tau_{2}\right) \frac{\partial \pi_{2}}{\partial k_{2}}\right] \\
& =\gamma\left[\left(1-\tau_{1}\right)\left(1-k_{1}\right)-\left(1-\tau_{2}\right)\left(1-k_{2}\right)\right] .
\end{aligned}
$$

We can verify that the equality $\left(1-\tau_{1}\right)\left(1-k_{1}\right)=\left(1-\tau_{2}\right)\left(1-k_{2}\right)$ holds when the system is at its steady state: $\dot{k}_{1}(t)=0$.

The objective function of policymaker $j(=1,2)$ is

$$
W_{j}\left(k_{j}\right)=\max _{\tau_{j}(t)} J_{j}=\int_{0}^{\infty} e^{-\rho t} \Omega_{j}(t) d t=\int_{0}^{\infty} e^{-\rho t}\left[\left(1-\tau_{j}\right) \pi_{j}+\theta \tau_{j} \pi_{j}\right] d t,
$$

subject to the motion equation (4).

\section{The Benchmark Case}

For purpose of comparison, we first analyze the static game as a benchmark case. We assume that the capital adjustment process occurs instantaneously and that the system is at its steady state right from the start.

The equilibrium condition of capital allocation between the two jurisdictions is such that the relative net marginal profit on capital is equalized across both countries. Thus, we have

$$
\left(1-\tau_{1}\right) \frac{\partial \pi_{1}}{\partial k_{1}}=\left(1-\tau_{2}\right) \frac{\partial \pi_{2}}{\partial k_{2}}, \text { that is }\left(1-\tau_{1}\right)\left(1-k_{1}\right)=\left(1-\tau_{2}\right)\left(1-k_{2}\right) .
$$

It follows that capital investment in countries 1 and 2 is respectively given by

$$
\begin{aligned}
k_{1}^{s} & =\frac{1-\tau_{1}}{2-\tau_{1}-\tau_{2}}, \\
k_{2}^{s} & =\frac{1-\tau_{2}}{2-\tau_{1}-\tau_{2}} .
\end{aligned}
$$


The superscript $s$ stands for "static". The policymakers of both jurisdictions choose non-cooperatively the tax rates, $\tau_{j}$ that maximize social welfare $\Omega_{j}$.

$$
\max _{\tau_{j}} \Omega_{j}=\left[1+\tau_{j}(\theta-1)\right] \pi_{j}
$$

The governments' objective functions are concave in their own tax rates $\left(\frac{\partial^{2} \Omega_{j}}{\partial \tau_{j}^{2}}<0\right)$. The standard first order condition for country $j(=1,2)$ yields the following result

$$
\pi_{j}=-\left(\frac{1}{\theta-1}+\tau_{j}\right)\left(1-k_{j}\right) \frac{\partial k_{j}}{\partial \tau_{j}}
$$

Using (6) and (7), equation (9) yields

$$
\begin{aligned}
& \pi_{1}=\frac{\frac{1}{\theta-1}+\tau_{1}}{2-\tau_{1}-\tau_{2}}\left(1-k_{1}^{s}\right)^{2}, \\
& \pi_{2}=\frac{\frac{1}{\theta-1}+\tau_{2}}{2-\tau_{1}-\tau_{2}}\left(1-k_{2}^{s}\right)^{2}
\end{aligned}
$$

for countries 1 and 2, respectively. Given that the countries are symmetric, we can write that $k_{1}^{s}=k_{2}^{s}$. It follows that $\pi_{1}=\pi_{2}$ given that $\pi_{j}=k_{j}-\frac{k_{j}^{2}}{2}$ for $j(=1,2)$.

Thus, we can conclude:

Proposition 1 In the static game there is a unique symmetric Nash equilibrium given by

$$
\tau_{1}^{s}=\tau_{2}^{s}=\frac{3 \theta-4}{4(\theta-1)}
$$

and the equilibrium level of capital invested in country $j(=1,2)$ is

$$
k_{1}^{s}=k_{2}^{s}=\frac{1}{2} .
$$

The above results show that according to the value of $\theta$ the governments can also compete in subsidies 5 . In this case we have $\tau_{j}<0(j=1,2)$ and the social welfare function $\Omega_{j}=\left(1-\tau_{j}\right) \pi_{j}+$ $\theta \tau_{j} \pi_{j}$ can be interpreted as follows. The first term is the income generated in country $j$ augmented

\footnotetext{
${ }^{10}$ These subsidies can be funded by taxing an inelastically supplied factor like land.
} 
by subsidies and the second (negative) term is the amount of forgone public goods expenditures. We can thus distinguish two different cases.

Corollary 1 In the static game each government can either tax the firm's profits or provide a subsidy. More precisely,

(1) If $\theta>\frac{4}{3}$, countries compete in taxes.

(2) If $1<\theta<\frac{4}{3}$, countries compete in subsidies.

When the decision makers put a sufficiently high relative valuation $\left(\theta>\frac{4}{3}\right)$ on public goods (financed by tax revenues), they compete in taxes. However, when they put a sufficiently high relative valuation $\left(1<\theta<\frac{4}{3}\right)$ on private consumption, they compete in subsidies. There are various reasons why decision makers can favor public over private goods or vice versa. There can be the desire to alleviate domestic unemployment (Haaparanta, 1996) or the attempt to realize scale economies with respect to the provision of public goods (Black and Hoyt, 1989) or the possibility to transfer advanced technology (Barros and Cabral, 2000), etc. These aspects are however beyond the scope of the present paper.

\section{Open-loop Nash Equilibrium: steady state and stability}

We now extend the above analysis and focus on dynamic competition. Now, capital does not adjust instantaneously. In a first step, we assume that each jurisdiction adopts an open-loop strategy when designing its optimal decision path. In other words, the jurisdictions commit and stick to a taxation policy decided at an initial date.

In order to solve the open-loop game between the jurisdictions, we use the Pontryagin's maximum principle. We derive a canonical system of ordinary differential equations satisfying the optimal decision trajectories. We know (see Dockner et al., 2000) that the Hamiltonian of our differential game is strictly concave in the state variable. As a consequence, the necessary optimality conditions are also sufficient (for a proof see Appendix A.1). 
The first order conditions yield

$$
\begin{aligned}
\dot{k}_{1}(t) & =\gamma\left[\left(1-\tau_{1}\right)\left(1-k_{1}\right)-\left(1-\tau_{2}\right)\left(1-k_{2}\right)\right], \\
\dot{\lambda}_{1}(t) & =\left[\rho+\gamma\left(2-\tau_{1}-\tau_{2}\right)\right] \lambda_{1}-\left[1+\tau_{1}(\theta-1)\right]\left(1-k_{1}\right), \\
\dot{\lambda}_{2}(t) & =\left[\rho+\gamma\left(2-\tau_{1}-\tau_{2}\right)\right] \lambda_{2}+\left[1+\tau_{2}(\theta-1)\right]\left(1-k_{2}\right), \\
(\theta-1) \pi_{1}(t) & =\gamma \lambda_{1}\left(1-k_{1}\right), \\
(\theta-1) \pi_{2}(t) & =-\gamma \lambda_{2}\left(1-k_{2}\right), \\
\text { and } \lim _{t \rightarrow \infty} e^{-\rho t} \lambda_{j} k_{j} & =0 \text { (transversality condition). }
\end{aligned}
$$

This system contains one state variables $(k)$, two costate variables $\left(\lambda_{j}\right.$ with $\left.j=1,2\right)$ and two choice variables $\left(\tau_{j}\right.$ with $\left.j=1,2\right)$.

The steady state is defined as the rest point of the above canonical system and is obtained by setting $\dot{k}=0$ and $\dot{\lambda}_{1}(t)=\dot{\lambda}_{2}(t)=0$. Thus, we obtain the following conditions:

$$
\begin{aligned}
\left(1-\tau_{1}\right)\left(1-k_{1}\right) & =\left(1-\tau_{2}\right)\left(1-k_{2}\right), \\
{\left[\rho+\gamma\left(2-\tau_{1}-\tau_{2}\right)\right] \lambda_{1} } & =\left[1+\tau_{1}(\theta-1)\right]\left(1-k_{1}\right), \\
{\left[\rho+\gamma\left(2-\tau_{1}-\tau_{2}\right)\right] \lambda_{2} } & =-\left[1+\tau_{2}(\theta-1)\right]\left(1-k_{2}\right), \\
(\theta-1) \pi_{1} & =\gamma \lambda_{1}\left(1-k_{1}\right), \\
(\theta-1) \pi_{2} & =-\gamma \lambda_{2}\left(1-k_{2}\right) .
\end{aligned}
$$

Equation (18) characterizes the steady state condition for a firm investing in country $j(=1,2)$. More precisely, if (18) holds, the relative net marginal profit on capital is the same in both countries. It follows that the steady state level of capital $k_{1}^{o}$ invested in country 1 is

$$
k_{1}^{o}=\frac{1-\tau_{1}}{2-\tau_{1}-\tau_{2}} .
$$

The superscript $o$ stands for "open-loop". Similarly, the steady state level of capital $k_{2}^{o}$ invested 
in country 2 is

$$
k_{2}^{o}=\frac{1-\tau_{2}}{2-\tau_{1}-\tau_{2}} .
$$

Equations (19) and (20) result from the first order conditions relative to the invested capital $k_{j}$ (with $j=1,2$ ). The left-hand side of (19) represents the discounted future losses in tax revenues in country 1 resulting from a current capital inflow. Indeed, additional capital flowing into country 1 decreases the net marginal profit of the subsidiary located there. This will induce capital relocation in country 2 in future periods. Consequently, future tax revenues will decrease in country 1 . The right-hand side of equation (19) stands for the government's gain in tax revenues induced by a marginal increase of capital in country 1. Equation (20) can be interpreted in the same way. The steady state requires equality between the just highlighted effects and consequently, $k_{j}$ does not change anymore. By reformulating equation (19), we obtain the (steady state) shadow value of the capital investment in country 1 :

$$
\lambda_{1}^{o}=\frac{\left[1+\tau_{1}(\theta-1)\right]\left(1-k_{1}\right)}{\rho+\gamma\left(2-\tau_{1}-\tau_{2}\right)} .
$$

Similarly, equation (20) yields the (steady state) shadow value of the MNC's investment in country 2:

$$
\lambda_{2}^{o}=-\frac{\left[1+\tau_{2}(\theta-1)\right]\left(1-k_{2}\right)}{\rho+\gamma\left(2-\tau_{1}-\tau_{2}\right)} .
$$

Equations (21) and 22 result from the first order conditions relative to the tax rate $\tau_{j}$ (with $j=1,2)$. An increase in country $j$ 's tax rate has two effects. On one side, it increases government's $j$ tax revenues (see left-hand side of equations (21) and (22)) and on the other side, it induces future losses in tax revenues due to the outflow of capital following the increase in the tax rate (see right-hand side of equations (21) and (22)). The equilibrium tax rate of country $j$ requires that both effects are equal.

By rewriting conditions (21) and (22) we obtain:

$$
\begin{aligned}
& \pi_{1}=\frac{\gamma \lambda_{1}\left(1-k_{1}\right)}{\theta-1} \\
& \pi_{2}=\frac{\gamma \lambda_{2}\left(1-k_{2}\right)}{\theta-1}
\end{aligned}
$$


The profit of the MNC realized in country $j$ equals the relative net marginal profit on capital $\left(\frac{\partial \pi_{j}}{\partial k_{j}}=1-k_{j}\right)$ multiplied by the shadow price $\lambda_{j}$ and the adjustment factor $\gamma$. Substituting $(23)$, (24), 25) and (26) into (27) and 28) yields the optimal tax rate $\tau_{j}^{o} \in(0,1)$ and the steady state value of the variables $k_{j}^{o}, \lambda_{j}^{o}(j=1,2)$.

Proposition 2 The above described dynamic game has a unique symmetric open-loop Nash equilibrium that is given by

$$
\tau_{1}^{o}=\tau_{2}^{o}=\frac{\frac{3}{2 \gamma}(\theta-1)(2 \gamma+\rho)-1}{4(\theta-1)} .
$$

The equilibrium level of capital invested in country $j(=1,2)$ is given by

$$
k_{1}^{o}=k_{2}^{o}=\frac{1}{2}
$$

Furthermore, the steady state is a saddle point of the canonical system and locally asymptotically stable in the state space.

The proof of this proposition is provided in Appendix A.2. Basing on Fershtman and Muller (1984, 1986), we can prove the following proposition.

Proposition 3 The unique symmetric Nash equilibrium highlighted in Proposition 2 is also globally asymptotically stable.

Similar to the static game in the previous subsection, the results presented in Proposition 2 demonstrate that the governments can also provide subsidies to attract foreign capital. This is in line with Haufler and Wooton(1999). The following conclusions can be drawn

Corollary 2 The governments can either tax profits or pay a subsidy. More precisely,

(I) If $1<\theta<1+\frac{2 \gamma}{3(2 \gamma+\rho)}$, we have a subsidy competition game $\left(\tau_{j}^{o}<0\right)$.

(II) If $\theta>1+\frac{2 \gamma}{3(2 \gamma+\rho)}$, we have a tax competition game $\left(\tau_{j}^{o} \in(0,1]\right)$. Moreover,

(II.1) if $\gamma>\frac{3}{2} \rho$, then the optimal tax rate is $\tau_{j}^{o} \in(0,1)$.

(II.2) if $\gamma<\frac{3}{2} \rho$ and 


$$
\begin{aligned}
& \text { (II.2.a) if } 1+\frac{2 \gamma}{3(2 \gamma+\rho)}<\theta<1+\frac{2 \gamma}{3 \rho-2 \gamma} \text {, then the optimal tax rate is } \tau_{j}^{o} \in(0,1) \text {; } \\
& \text { (II.2.b) if } \theta>1+\frac{2 \gamma}{3 \rho-2 \gamma} \text {, then both governments impose the highest possible tax rate }\left(\tau_{j}^{o}=\right. \\
& \left.\tau^{\max }=1\right) .
\end{aligned}
$$

The governments' decision to tax profits or to grant subsidies depends on how much they weigh up private consumption against public consumption. If the policymakers put a relatively low weight $\left(\theta<1+\frac{2 \gamma}{3(2 \gamma+\rho)}\right)$ on public consumption (or tax revenue) or equivalently a relatively high weight on private consumption, they grant subsidies in order to attract foreign capital.

Moreover, the above corollary shows that it is not excluded that the competing jurisdictions tax profit at the highest possible rate $\left(\tau^{\max }=1\right)$ that saturates firms' participation constraint $\left(\left(1-\tau_{j}\right) \pi_{i} \geq 0\right)$. This case occurs if capital adjustment is relatively sluggish $\left(\gamma<\frac{3}{2} \rho\right)$ and the marginal valuation of public goods is high enough (i.e. $\theta>1+\frac{2 \gamma}{3 \rho-2 \gamma}$ ), which means that the jurisdictions put a high weight on tax revenues. In all other cases, the optimal tax rate is lower than the highest possible rate, namely $\tau_{j}^{o s} \in(0,1)$.

Finally, increased capital mobility (higher $\gamma$ ) intensifies tax and subsidy competition given that $\frac{\partial \tau_{j}^{o}}{\partial \gamma}=\frac{24 \rho(\theta(2-\theta)-1)}{(8 \gamma(\theta-1))^{2}}<0$. Moreover, the higher the marginal valuation of public goods, the higher (lower) the tax (subsidy) rate of country $j$, as $\frac{\partial \tau_{j}^{o}}{\partial \theta}=\frac{2}{8(\theta-1)^{2}}>0$. Finally, country $j$ 's tax rate (subsidy) increases with the discount rate of the public decision makers given that $\frac{\partial \tau_{j}^{o}}{\partial \rho}=\frac{3}{8 \gamma}>0$. Indeed, the higher the discount factor $\rho$ the less the policymakers care about future tax losses due to capital outflows induced by higher tax rates or lower subsidies.

\section{Markovian Nash Equilibrium}

Now, we assume that the jurisdictions adopt a Markovian rule when designing their optimal decision path. This means that the tax rates are continuously reset in response to the dynamics of the states of the world.

We define the Bellman optimal value of the objective function of country $j(=1,2)$ as $V_{j}\left(k_{j}\right)=$ $\max _{\tau_{j}} J_{j}, \forall k_{j}$. The Bellman's value-function $V_{j}$ of the policymaker in country $j$ must satisfy the 
following Hamilton-Jacobi-Bellman equation, with $k_{2}=1-k_{1}$ :

$$
\begin{aligned}
& \rho V_{1}\left(k_{1}\right)=\max _{\tau_{1}}\left\{\left[1+\tau_{1}(t)(\theta-1)\right] \pi_{1}(t)+\frac{\partial V_{1}}{\partial k_{1}} \gamma\left[\left(1-\tau_{1}\right) \frac{\partial \pi_{1}}{\partial k_{1}}-\left(1-\tau_{2}\right) \frac{\partial \pi_{2}}{\partial k_{2}}\right]\right\}, \\
& \rho V_{2}\left(k_{2}\right)=\max _{\tau_{2}}\left\{\left[1+\tau_{2}(t)(\theta-1)\right] \pi_{2}(t)-\frac{\partial V_{2}}{\partial k_{2}} \gamma\left[\left(1-\tau_{1}\right) \frac{\partial \pi_{1}}{\partial k_{1}}-\left(1-\tau_{2}\right) \frac{\partial \pi_{2}}{\partial k_{2}}\right]\right\} .
\end{aligned}
$$

The first-order conditions with respect to the choice variables $\tau_{1}$ and $\tau_{2}$ yield

$$
\begin{aligned}
& \pi_{1}=\frac{\gamma \frac{\partial V_{1}}{\partial k_{1}}\left(1-k_{1}\right)}{\theta-1}, \\
& \pi_{2}=\frac{\gamma \frac{\partial V_{2}}{\partial k_{2}}\left(1-k_{2}\right)}{\theta-1} .
\end{aligned}
$$

These conditions are similar to the necessary and sufficient conditions (27) and (28) obtained in the open-loop game.

The above first-order conditions can be rewritten in the following way

$$
\begin{aligned}
& \frac{\partial V_{1}}{\partial k_{1}}=\frac{(\theta-1) \pi_{1}}{\gamma\left(1-k_{1}\right)}=\frac{\theta-1}{\gamma} \frac{k_{1}-k_{1}^{2} / 2}{\left(1-k_{1}\right)}, \\
& \frac{\partial V_{2}}{\partial k_{2}}=\frac{(\theta-1) \pi_{2}}{\gamma\left(1-k_{2}\right)}=\frac{\theta-1}{\gamma} \frac{k_{2}-k_{2}^{2} / 2}{\left(1-k_{2}\right)} .
\end{aligned}
$$

Knowing that $k_{2}=1-k_{1}$, the strategic variables can be rewritten as $\tau_{1}=\tau_{1}\left(k_{1}\right)$ and $\tau_{2}=\tau_{2}\left(k_{2}\right)$. In other words, country $j$ 's Markovian choice variable only depends on the state variable of country $j$ and is independent of the other country's stock of capital. We can thus apply the envelope theorem

$$
\begin{aligned}
& \rho \frac{\partial V_{1}}{\partial k_{1}}=\left[1+\tau_{1}(\theta-1)\right] \frac{\partial \pi_{1}}{\partial k_{1}}+\frac{\partial^{2} V_{1}}{\partial k_{1}^{2}} \gamma\left[\left(1-\tau_{1}\right) \frac{\partial \pi_{1}}{\partial k_{1}}-\left(1-\tau_{2}\right) \frac{\partial \pi_{2}}{\partial k_{2}}\right]+\frac{\partial V_{1}}{\partial k_{1}} \gamma\left(1-\tau_{1}\right) \frac{\partial^{2} \pi_{1}}{\partial k_{1}^{2}} \\
& \rho \frac{\partial V_{2}}{\partial k_{2}}=\left[1+\tau_{2}(\theta-1)\right] \frac{\partial \pi_{2}}{\partial k_{2}}-\frac{\partial^{2} V_{2}}{\partial k_{2}^{2}} \gamma\left[\left(1-\tau_{1}\right) \frac{\partial \pi_{1}}{\partial k_{1}}-\left(1-\tau_{2}\right) \frac{\partial \pi_{2}}{\partial k_{2}}\right]+\frac{\partial V_{2}}{\partial k_{2}} \gamma\left(1-\tau_{2}\right) \frac{\partial^{2} \pi_{2}}{\partial k_{2}^{2}} \cdot
\end{aligned}
$$


In the steady state we have $\dot{k}_{i}=0$, which implies

$$
\left(1-\tau_{1}\right) \frac{\partial \pi_{1}}{\partial k_{1}}=\left(1-\tau_{2}\right) \frac{\partial \pi_{2}}{\partial k_{2}}
$$

Substituting (35) and the first-order conditions (31) and (32) into (33) and (34), we obtain the following relationship between the tax rates and the capital stocks:

$$
\begin{aligned}
& \left(\rho+\gamma\left(1-\tau_{1}\right)\right) \pi_{1}=\gamma\left[\frac{1}{\theta-1}+\tau_{1}\right]\left(\frac{\partial \pi_{1}}{\partial k_{1}}\right)^{2}=\gamma\left[\frac{1}{\theta-1}+\tau_{1}\right]\left(1-k_{1}\right)^{2} \\
& \left(\rho+\gamma\left(1-\tau_{2}\right)\right) \pi_{2}=\gamma\left[\frac{1}{\theta-1}+\tau_{2}\right]\left(\frac{\partial \pi_{2}}{\partial k_{2}}\right)^{2}=\gamma\left[\frac{1}{\theta-1}+\tau_{2}\right]\left(1-k_{2}\right)^{2}
\end{aligned}
$$

Because we assume symmetry ${ }^{11}\left(\tau_{1}^{m}=\tau_{2}^{m}\right)$, equation 35 yields

$$
k_{1}^{m}=k_{2}^{m}=\frac{1}{2}
$$

where the superscript $m$ stands for "Markovian". By substituting (38) into (36), we obtain the equilibrium tax rates

$$
\tau_{1}^{m}=\tau_{2}^{m}=\frac{3(\theta-1)(\gamma+\rho)-2 \gamma}{5 \gamma(\theta-1)}
$$

The following proposition states the above results.

Proposition 4 The above described game has a unique symmetric Markovian Nash equilibrium, which is

$$
\tau_{1}^{m}=\tau_{2}^{m}=\frac{\frac{3}{\gamma}(\theta-1)(\gamma+\rho)-2}{5(\theta-1)}
$$

The equilibrium level of capital invested in country $j=1,2$ is

$$
k_{1}^{m}=k_{2}^{m}=\frac{1}{2} .
$$

\footnotetext{
${ }^{11}$ Without this assumption, the problem should be solved by combining equations (36), (37), (35) and the condition $k_{1}+k_{2}=1$. We then have 4 equations with 4 unknowns: $\tau_{1}, \tau_{2}, k_{1}$ and $k_{2}$.
} 
The competing governments can use subsidies to attract foreign capital under the following conditions

Corollary 3 (I) If $1<\theta<1+\frac{2 \gamma}{3(\gamma+\rho)}$, we have a subsidy competition game $\left(\tau_{j}^{m}<0\right)$.

(II) If $\theta>1+\frac{2 \gamma}{3(\gamma+\rho)}$, we have a tax game $\left(\tau_{j}^{m} \in(0,1]\right)$. Furthermore,

(II.1) if $\gamma>\frac{3}{2} \rho$, the optimal tax rate is $\tau_{j}^{m} \in(0,1)$.

(II.2) if $\gamma<\frac{3}{2} \rho$ and

(II.2.a) if $1+\frac{2 \gamma}{3(\gamma+\rho)}<\theta<1+\frac{2 \gamma}{3 \rho-2 \gamma}$, the optimal tax rate is $\tau_{j}^{m} \in(0,1)$;

(II.2.b) if $\theta>1+\frac{2 \gamma}{3 \rho-2 \gamma}$, the governments can impose high tax rates such that $\tau_{j}^{m}=\tau^{\max }=1$.

As in the open-loop equilibrium, the governments' decision to tax profits or to provide a subsidy depends on their social preference for public relative to private goods. If the policymakers favor private over public consumption by putting a relatively low weight on tax revenue $\left(\theta<1+\frac{2 \gamma}{3(\gamma+\rho)}\right)$, they grant subsidies to attract capital (case I). If the decision makers put a relatively high marginal valuation $\left(\theta>1+\frac{2 \gamma}{3(\gamma+\rho)}\right)$ on public goods, they tax profits (case II). Once more, the above corollary shows that it is not excluded that the competing jurisdictions tax profit at the highest possible rate $\left(\tau^{\max }=1\right)$ that saturates firms' participation constraint $\left(\left(1-\tau_{j}\right) \pi_{i} \geq 0\right)$ (case II.1). As in the open-loop equilibrium, this occurs if capital adjustment is relatively sluggish (i.e. $\gamma<\frac{3}{2} \rho$ ) and the marginal valuation of public goods is high enough (i.e. $\theta>1+\frac{2 \gamma}{3 \rho-2 \gamma}$ ). In all other cases, the optimal tax rate is lower than the highest possible rate, namely $\tau_{j}^{m} \in(0,1)$.

We see that increased capital mobility (higher $\gamma$ ) intensifies tax and subsidy competition given that $\frac{\partial \tau_{j}^{m}}{\partial \gamma}=\frac{15 \rho(\theta(2-\theta)-1)}{(5 \gamma(\theta-1))^{2}}<0$. Moreover, the higher the marginal valuation of public goods, the higher country $j^{\prime}$ s tax rate, as $\frac{\partial \tau_{j}^{m}}{\partial \theta}=\frac{2}{5(\theta-1)^{2}}>0$. Finally, country $j$ 's tax rate increases with the discount rate of the public decision makers given that $\frac{\partial \tau_{j}^{m}}{\partial \rho}=\frac{3}{5 \gamma}>0$. 


\section{Welfare Comparisons}

We now compare welfare between the different settings highlighted above. We consider alternatively the tax game (i.e. $\theta>\bar{\theta}$ ) and then the subsidy game (i.e. $1<\theta<\underline{\theta}$ ), with

$$
\begin{aligned}
& \bar{\theta} \equiv \max \left\{\frac{4}{3}, 1+\frac{2 \gamma}{3(2 \gamma+\rho)}, 1+\frac{2 \gamma}{3(\gamma+\rho)}\right\}=\max \left\{\frac{4}{3}, 1+\frac{2 \gamma}{3(\gamma+\rho)}\right\}, \\
& \underline{\theta} \equiv \min \left\{\frac{4}{3}, 1+\frac{2 \gamma}{3(2 \gamma+\rho)}, 1+\frac{2 \gamma}{3(\gamma+\rho)}\right\}=1+\frac{2 \gamma}{3(2 \gamma+\rho)} .
\end{aligned}
$$

In the static game, the equilibrium social welfare is

$$
\Omega_{j}^{s}=\left[1+\tau_{j}^{s}(\theta-1)\right] \pi_{j}^{s}=\frac{3}{8}\left(1+\tau_{j}^{s}(\theta-1)\right) .
$$

The equilibrium social welfare obtained in the open-loop and Markovian game are respectively

$$
\begin{aligned}
\Omega_{j}^{o} & =\frac{3}{8}\left(1+\tau_{j}^{o}(\theta-1)\right), \\
\Omega_{j}^{m} & =\frac{3}{8}\left(1+\tau_{j}^{m}(\theta-1)\right) .
\end{aligned}
$$

We see that comparing social welfare in different settings is equivalent to comparing the equilibrium tax rates/subsidies. Consequently, lower equilibrium tax rates (respectively higher subsidy rates) are consistent with lower social welfare. In other words, the fiercer tax competition is the lower countries' social welfare will be. 


\subsection{Tax game: $\theta>\bar{\theta}$}

We assume that the jurisdictions compete in taxes, i.e. $\theta>\bar{\theta}$. Equilibrium tax comparisons yield

$$
\begin{aligned}
& \text { (i) } \tau_{j}^{s}<\tau_{j}^{o} \text {, and } \tau_{j}^{s}=\lim _{\rho \rightarrow 0} \tau_{j}^{o}=\lim _{\gamma \rightarrow+\infty} \tau_{j}^{o}, \\
& \text { (ii) } \tau_{j}^{o}-\tau_{j}^{m}=\frac{3}{20}\left(\frac{\theta}{\theta-1}-\frac{3 \rho}{2 \gamma}\right)>0, \\
& \text { (iii) } \tau_{j}^{m}-\tau_{j}^{s}=\frac{3}{20}\left(\frac{4 \rho}{\gamma}-\frac{\theta}{\theta-1}\right)\left\{\begin{array}{l}
>0, \text { if } \gamma<4 \rho \text { and } \theta>1+\frac{\gamma}{4 \rho-\gamma}, \\
<0, \text { otherwise. }
\end{array}\right.
\end{aligned}
$$

Because comparing social welfare is equivalent to comparing equilibrium tax rates, we conclude

Proposition 5 - Social welfare is higher in an open-loop equilibrium relative to a static equilibrium,

- social welfare is lower in a Markovian equilibrium relative to an open-loop equilibrium,

- social welfare is higher in a Markovian equilibrium relative to a static equilibrium when the speed of capital reallocation is low $(\gamma<4 \rho)$ and the policymakers put a relatively high weight on public consumption $\left(\theta>1+\frac{\gamma}{4 \rho-\gamma}\right)$. Otherwise, welfare is lower in the Markovian game.

- For $\rho \rightarrow 0$ and/or $\gamma \rightarrow+\infty$, the open-loop equilibrium converges to the static equilibrium.

The ranking of social welfare corresponding to the different cases is summarized as follows

$$
\Omega_{j}^{m}<\Omega_{j}^{s}<\Omega_{j}^{o}
$$

If the governments adopt an open-loop rule, the equilibrium tax rates and thus social welfare are higher in the dynamic version relative to the static one. Recall that the static case in which capital moves in one shot as a reaction to tax differences corresponds analytically notably to the case where the speed of adjustment $(\gamma)$ tends to infinity. Consequently, in the open-loop case (with a finite $\gamma$ ) capital movement is less responsive to tax differences compared to the static case (with $\gamma$ tending to infinity). It follows that competition between jurisdictions is less fierce in the 
open-loop case. This explains why the equilibrium tax rates, and consequently social welfare, are higher in the open-loop equilibrium relative to the static equilibrium.

Moreover, tax rates are higher in an open-loop equilibrium relative to a Markovian equilibrium. To understand the intuition behind this result, note that in the Markovian setting each government takes into account its rival's reaction to variations in the state variable (capital). More precisely, the policymakers continuously update their tax rates as a response to changing capital investments, which induces fierce interjurisdictional competition. On the contrary, tax rates are not continuously updated in the open-loop game. A path of tax rates is determined at the start of the game and no future update is made. Governments commit to stick durably to their tax policy, which leads to less intense competition ${ }^{12}$ and higher tax rates.

Consequently, social welfare is higher in an open-loop equilibrium relative to both, the Markovian equilibrium and the static equilibrium.

Finally, in a Markovian game, tax rates are lower than in the static game, if the speed of capital adjustment is high and the marginal valuation of public goods is sufficiently low. In this case, tax competition is relatively fiercer in the Markovian game. This is not the case, if capital adjustment is relatively sluggish and the jurisdictions put a high weight on collecting tax revenue.

Finally, note that the static equilibrium is the limit case of an open-loop equilibrium with either $\rho=$ 0 (the policymakers are perfectly "time-indifferent") or $\gamma=+\infty$ ( capital adjusts instantaneously). The Markovian equilibrium, however, never converges to the static equilibrium as $\lim _{\rho \rightarrow 0} \tau_{j}^{m s}=$ $\lim _{\gamma \rightarrow+\infty} \tau_{j}^{m s}=\frac{3(\theta-1)-2}{5(\theta-1)}<\tau_{j}^{s s}$.

\subsection{Subsidy competition game: $1<\theta<\underline{\theta}$}

In the following we assume that the jurisdictions use subsidies to attract capital $(1<\theta<\underline{\theta})$. For the sake of simplicity, we set $s_{j}^{i}=-\tau_{j}^{i}(i=o, s, m)$. As in the above subsection, direct

\footnotetext{
${ }^{12}$ The fact that policymakers' commitment weakens competition explains why policymakers who adopt the open-loop behavior are less likely to engage in subsidy competition. Indeed, from the definitions of $\bar{\theta}$ and $\underline{\theta}$ it is straightforward to show that if $\underline{\theta}<\theta<\frac{4}{3}$ and $\rho<\gamma$, governments compete in taxes in the open-loop case while they compete in subsidies if they play a Markovian game.
} 
calculations yield

$$
\begin{aligned}
& \text { (i) } s_{j}^{o}-s_{j}^{s}<0=-\frac{3 \rho}{2 \gamma}(\theta-1)<0 \text { and } s_{j}^{s}=\lim _{\rho \rightarrow 0} s_{j}^{o}=\lim _{\gamma \rightarrow+\infty} \tau_{j}^{o}, \\
& \text { (ii) } s_{j}^{m}-s_{j}^{o}=\frac{3}{20}\left(\frac{\theta}{\theta-1}-\frac{3 \rho}{2 \gamma}\right)>0, \\
& \text { (iii) } s_{j}^{s}-s_{j}^{m}=\frac{3}{20}\left(\frac{4 \rho}{\gamma}-\frac{\theta}{\theta-1}\right)\left\{\begin{array}{l}
>0, \text { if } \gamma<\frac{5}{8} \rho \text { and } 1+\frac{\gamma}{4 \rho-\gamma}<\theta<\underline{\theta}, \\
<0, \text { otherwise. }
\end{array}\right.
\end{aligned}
$$

Because social welfare comparisons are equivalent to equilibrium subsidy comparisons, we can conclude

\section{Proposition 6 - Social welfare is higher in an open-loop relative to a static equilibrium,}

- social welfare is lower in a Markovian relative to an open-loop equilibrium,

- social welfare is lower in a Markovian relative to a static equilibrium, except for the case where the speed of capital reallocation is low (i.e. $\gamma<\frac{5}{8} \rho$ ) and the policymakers' weight assigned to public consumption is not too low (i.e. $1+\frac{\gamma}{4 \rho-\gamma}<\theta<\underline{\theta}$ ).

- for $\rho \rightarrow 0$ and/or $\gamma \rightarrow+\infty$ the open-loop game converges to the static equilibrium.

We get similar results as in the tax competition case. Indeed, if both governments adopt an openloop strategy, subsidies are lower and thus social welfare is higher relative to the static setting. Again, this is due to the fact that capital movements are less responsive to subsidy differences in the open-loop case than in the static case. Moreover, social welfare is higher in an open-loop equilibrium relative to a Markovian equilibrium. In other words, the policymakers' commitment to subsidy payments leads to less competition and a higher overall welfare.

If the governments adopt a Markovian behavior, social welfare is lower than in the static game, if the speed of capital adjustment is high enough and the marginal valuation of public goods is sufficiently low. Indeed, if the policymakers opt for a Markovian behavior, they continuously update their subsidy rates as a response to changing capital investment. This makes jurisdictional competition fiercer. However, if capital adjustment is relatively sluggish and decision makers pay 
sufficient importance to public consumption, social welfare is relatively higher in the Markovian equilibrium than in the static one.

\section{Conclusion}

The focus of the paper is on the dynamic relevance of interjurisdictional competition. The existing literature is mainly based on static models, in which capital stocks adjust instantaneously to policy changes and tax rates don't evolve over time. In the framework we develop, the dynamics are characterized by time-varying tax rates and imperfect capital adjustment.

There are two different ways of modeling dynamic tax competition. One way is to assume that the competing jurisdictions play an open-loop game in which they commit initially to a tax path without further update. Another is to model a Markovian game where the competing countries continuously update their tax rates according to their capital stock. Commitment to predetermined tax rates leads to a less intense competition relative to Markovian and static games. As a result, social welfare is relatively higher. However, comparing the outcome and social welfare between static and Markovian games is not straightforward. In a Markovian game, tax rates are lower than in the static game, if the speed of capital adjustment is high and the marginal valuation of public goods is sufficiently low. In this case, tax competition is relatively fiercer in the Markovian game. This is not the case, if capital adjustment is relatively sluggish and the jurisdictions put a high weight on collecting tax revenue.

Moreover, playing a Markovian or an open-loop game is not necessarily a matter of choice. Countries may commit to a future path of tax rates to be attractive to foreign investments but commitment may also be imposed by international cooperation agreements.

All in all, static models provide an incomplete analysis of inter-jurisdictional tax competition. In a world, in which capital can flow more or less sluggishly form one jurisdiction to another as a response to policy changes and governments interact differently according to specific behavioral patterns (Markovian or open-loop), a dynamic setting is indispensable to analyze long-term outcomes.

In a future paper, it will be interesting to extend the present analysis to asymmetric countries (e.g. unequal size, different initial resource endowments, different productivity). Assuming different resource endowments would for example allow to investigate under which conditions tax, 
respectively subsidy competition could promote convergence across unequally developed countries. Furthermore, applying the current dynamic setting to asymmetric countries would enable a comparison between tax competition and tax harmonization. In this context, could the competing governments' commitment to stick to their tax policies for a given period lead to a more desirable outcome (in terms of social welfare) than tax harmonization? 


\section{References}

[1] Altshuler R. and Grubert H. (2006). Governments and Mulitinational Corporations in the Race to the Bottom. Tax Notes 41(5), 459-474.

[2] Barros P. and Cabral L. (2000). Competing for Foreign Direct Investment. Review of International Economics, 8(2), 360-371.

[3] Becker D. (2005). Dynamic Tax Competition and Public-Sector Modernisation. ThünenSeries of Applied Economic Theory, 56. Revised Version April 2008.

[4] Becker J. and Riedel N. (2012). Cross-boder tax effects on affiliate investment - Evidence from European multinationals. European Economic Review, 56, 436-450.

[5] Becker J., Fuest C., and Riedel N. (2012). Corporate tax effects on the quality and quantity of FDI. European Economic Review, 56, 1495-1511.

[6] Black A. and Hoyt W. (1989). Bidding for Firms. The American Economic Review, 97(5), 1249-1256.

[7] Bucovetsky S. and Smart M. (2006). The Efficiency Consequences of Local Revenue Equalization: Tax Competition and Tax Distortions. Journal of Public Economic Theory, 8, 119-144.

[8] Devereux, J.H. and Freeman, H. (1995). The impact of tax on foreign direct investment: empirical evidence and the implications for tax integration schemes. International Tax and Public Finance, 2, 85-106.

[9] Eggert W. and Itaya J. (2014). Tax Rate Harmonization, Renegotiation, and Asymmetric Tax Competition for Profits with Repeated Interaction. Journal of Public Economic Theory, $16(5), 796-823$.

[10] Fershtman Ch. and Muller E. (1984). Capital accumulation games of infinite duration. Journal of Economic Theory 33, 322-339.

[11] Fershtman Ch. and Muller E. (1986). Turnpike properties of capital accumulation games. Journal of Economic Theory 38, 167-177.

[12] Haaparanta S. (1996). Competition for Foreign Direct Investments. Journal of Public Economics, 63,141-153. 
[13] Han, Y., Pieretti P., Zanaj S., and Zou B. (2014). Asymmetric competition among nation states: A differential game approach. Journal of Public Economics, 119, 71-79.

[14] Hartmann D. (1984). Tax Policy and Foreign Direct Investment in the United States. National Tax Journal, 37, 475-487.

[15] Hartmann D. (1985). Tax Policy and Foreign Direct Investment. Journal of Public Economics, 26, 107-121.

[16] Haufler A. and Wooton I. (1999). Country Size and Tax Competition for Foreign Capital. Journal of Public Economics, 71, 121-139.

[17] Kamien M. and Schwartz N. (1981). Dynamic Optimization. New York:Elsevier North Holland.

[18] Kanbur, R. and Keen, M. (1993) Jeux Sans Frontières: Tax Competition and Tax Coordination when Countries differ in Size. American Economic Review 83(4), 877-893.

[19] Kato H. (1981). The importance of government commitment in attracting firms: A dynamic analysis of tax competition in an agglomeration economy. European Economic Review, 74, $57-78$.

[20] Slemrod, J. (1990a). Optimal Taxation and Optimal Tax Systems. Journal of Economic Perspectives, 4(1), 157-178.

[21] Slemrod, J. (1990b). Tax Effects on Foreign Direct Investment in the US: Evidence from a Cross-Country Comparison. Taxation in the Global Economy, University of Chicago Press

[22] Wildasin D.E. (2003). Fiscal competition in space and time. Journal of Public Economics, 87, 2571-2588.

[23] Wildasin D.E. (2011). Fiscal competition for imperfectly-mobile labor and capital: a comparative dynamic analysis. Journal of Public Economics, 95, 1312-1321.

[24] Wilson J.D. (1987). Trade, Capital Mobility, and Tax Competition. Journal of Political Economy, 95(4), 835-856.

[25] Wilson J.D. and Wildasin D.E. (2004). Capital Tax Competition: Bane or Boon. Journal of Public Economics, 88(6), 1065-1091 


\section{A Appendix}

\section{A.1 Proof of the necessary and sufficient conditions in Section 4}

Both jurisdictions' policymakers maximize their objective function subject to the law of motion of the capital allocation process

$$
\begin{aligned}
\max _{\tau_{j}(t)} J_{j} & =\int_{0}^{\infty} e^{-\rho t}\left(1-\tau_{j}(t)\right) \pi_{j}+\theta \tau_{j}(t) \pi_{j} d t, \\
\text { s.t. } \dot{k}(t) & =\gamma\left[\left(1-\tau_{1}\right)\left(1-k_{1}\right)-\left(1-\tau_{2}\right)\left(1-k_{2}\right)\right] .
\end{aligned}
$$

In order to derive the canonical system of ordinary differential equations, we use the present value Hamiltonians of country 1 and 2, which are given by

$$
\mathcal{H}_{1}\left(\tau_{1}, k_{1}, \lambda_{1}\right)=\left(1-\tau_{1}\right) \pi_{1}+\theta \tau_{1} \pi_{1}+\lambda_{1} \gamma\left[\left(1-\tau_{1}\right)\left(1-k_{1}\right)-\left(1-\tau_{2}\right)\left(1-k_{2}\right)\right]
$$

and

$$
\mathcal{H}_{2}\left(\tau_{2}, k_{2}, \lambda_{2}\right)=\left(1-\tau_{2}\right) \pi_{2}+\theta \tau_{2} \pi_{2}+\lambda_{2} \gamma\left[\left(1-\tau_{1}\right)\left(1-k_{1}\right)-\left(1-\tau_{2}\right)\left(1-k_{2}\right)\right]
$$

with $k_{2}=1-k_{1}$.

The standard first-order conditions for the open-loop equilibrium are given by

$$
\begin{aligned}
\dot{k}_{1}(t) & =\gamma\left[\left(1-\tau_{1}\right)\left(1-k_{1}\right)-\left(1-\tau_{2}\right)\left(1-k_{2}\right)\right], \\
\dot{\lambda}_{1}(t) & =\left(\rho+\gamma\left(2-\tau_{1}-\tau_{2}\right)\right) \lambda_{1}-\left[1+\tau_{1}(\theta-1)\right]\left(1-k_{1}\right), \\
\dot{\lambda}_{2}(t) & =\left(\rho+\gamma\left(2-\tau_{1}-\tau_{2}\right)\right) \lambda_{2}+\left[1+\tau_{2}(\theta-1)\right]\left(1-k_{2}\right), \\
(\theta-1) \pi_{1}(t) & =\gamma \lambda_{1}\left(1-k_{1}\right), \\
(\theta-1) \pi_{2}(t) & =-\gamma \lambda_{2}\left(1-k_{2}\right), \\
\text { and } \lim _{t \rightarrow \infty} e^{-\rho t} \lambda_{j} k_{j} & =0 \text { (transversality condition). }
\end{aligned}
$$

Let's now prove that the necessary conditions are also sufficient. For this purpose we demonstrate that all the possible corner solutions can be ruled out.

First, notice that the objective and the Hamiltonian functions are linear in the choice variable $\tau_{j}$ 
and social welfare equals the output generated in country $j(=1,2)$ if the two policymakers impose a tax rate of 0 . Because $\theta>1$, any tax rate $\tau_{j} \in(0,1)$ generates a higher social welfare than $\tau_{j}=0$ for $j=1,2$.. Consider now that one jurisdiction, say country 1 , unilaterally imposes a tax rate $\tau_{1}=1$ while the other imposes $\tau_{2}<1$. As a result, all the capital will move from country 1 to country 2 and the social welfare in country 1 will be 0 . Country 1 will react by reducing its tax rate and the pair of values $\left(\tau_{j}=1, \tau_{i}<1\right)$ with $i \neq j$ cannot be an equilibrium. Finally, assume that the two countries impose the highest tax rates $\tau_{1}=\tau_{2}=1$. This cannot be an equilibrium too, because each country has an incentive to underbid the other and thus to win all the market. Consequently, none of the above corner solutions are candidates for an optimum solution. The global maximum can only be an interior solution. We thus prove that the first order conditions are not only necessary but also sufficient.

Now, we show that the interior solution is unique.

The standard first-order conditions yield the steady state amount of capital invested by the MNC in country 1 that is

$$
k_{1}=\frac{1-\tau_{2}}{2-\tau_{1}-\tau_{2}} .
$$

Given the symmetric setting, we only look for symmetric solutions. For $\tau_{1}=\tau_{2}$, we have $k_{1}=$ $k_{2}=\frac{1}{2}$ and the steady state shadow value of the investment of the MNC in country 1 is given by

$$
\lambda_{1}=\frac{\left[1+\tau_{1}(\theta-1)\right] \frac{1}{2}}{\rho+\gamma\left(2-2 \tau_{1}\right)}
$$

Substituting (39) and (40) into (27) yields the optimal tax rate which is given by

$$
\tau_{1}=\frac{\frac{3}{2 \gamma}(\theta-1)(2 \gamma+\rho)-1}{4(\theta-1)} \in(0,1) .
$$

As a conclusion, the optimal solution is unique.

\section{A.2 Proof of the stability of Proposition 2}

Now, we prove the stability of the results in Proposition 2. 
The assumption that $\tau_{1}=\tau_{2}$ yields

$$
\begin{aligned}
\dot{k}=\gamma & {\left[\left(1-\tau_{1}\right)\left(1-k_{1}\right)-\left(1-\tau_{2}\right)\left(1-k_{2}\right)\right] } \\
& =\gamma\left(1-\tau_{2}\right)\left(1-2 k_{1}\right),
\end{aligned}
$$

and

$$
\dot{\lambda}_{1}=\left(\rho+2 \gamma\left(1-\tau_{2}\right)\right) \lambda_{1}-\left[1+\tau_{2}(\theta-1)\right]\left(1-k_{1}\right)
$$

Note that the choice variable $\tau_{2}$ is independent of the state and the costate variables, $k_{1}, \lambda_{1}$, of country 1 . It follows that the Jacobian matrix

$$
J\left(k_{1}^{o}, \lambda_{1}^{o}\right)=\left(\begin{array}{cc}
-2 \gamma\left(1-\tau_{2}^{o}\right) & 0 \\
1+\tau_{2}^{o}(\theta-1) & \rho+2 \gamma\left(1-\tau_{2}^{o}\right)
\end{array}\right)
$$

yields the eigenvalues

$$
\delta_{1}=-2 \gamma\left(1-\tau_{2}^{o}\right)<0 \text { and } \delta_{2}=\rho+2 \gamma\left(1-\tau_{2}^{o}\right)>0
$$

By symmetry, we obtain the same results for country 2.

Thus, we can state that the steady state is a saddle point of the canonical system and locally asymptotically stable in the state space. 